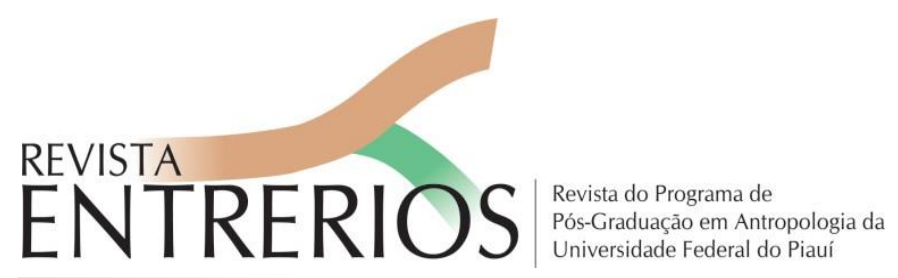

\title{
A metodologia da pesquisa comparativa em desastres
}

\section{The methodology of comparative research in disasters}

Marcos Mattedi Doutor em Ciências Sociais - UNICAMP Professor do Programa de Pós Graduação em Desenvolvimento Regional da Fundação Universidade Regional de Blumenau - PPGDR/FURB mattediblu@gmal.com Maria Roseli Rossi Avila Doutora em Desenvolvimento Regional - FURB mariaroselirossiavila@yahoo.com.br

Resumo: Resultados de pesquisas possibilitam compreender a dinâmica de incidência e impacto dos desastres sobre populaçoes e territórios. Tambem podem contribuir para refinar politicas públicas e ações governamentais de enfrentamento na área. Este artigo de cunho qualitativo, bibliográfico e exploratório não discute diretamente o tema dos desastres, mas trata da metodologia da pesquisa comparativa neste campo de estudos e nas Ciências Sociais. Apresenta um modelo de estratégias analíticas/metodológicas aplicado em pesquisa sobre 'a gestão dos desastres no Brasil com base no estudo comparativo de casos das secas no Piauí, queimadas em Rondônia e enchentes em Santa Catarina', desenvolvido no âmbito do doutorado em Desenvolvimento Regional na Universidade Regional de Blumenau, SC.

Palavras-Chave: Estudo comparativo; Ciências Sociais; desastres.

Abstract: Research results make it possible to understand the dynamics of incidence and impact of disasters on populations and territories. They can also contribute to refining public policies and government actions in the area. This qualitative, bibliographical and exploratory article does not directly discuss the theme of disasters, but deals with the methodology of comparative research in this field of studies and in the Social Sciences. It presents a model of analytical/methodological strategies applied in research on 'the management of disasters in Brazil based on the comparative case study of droughts in Piauí, fires in Rondônia and floods in Santa Catarina', developed under the doctoral program in Regional Development at Regional University of Blumenau, SC. Keywords: Comparative Study; Social Sciences; disasters.

\section{Introdução}

No mundo todo percebe-se o aumento do número, frequência e intensidade dos desastres. Clima e temperatura também têm sofrido alterações nunca vistas, segundo o $5^{\circ}$ Relatório do Painel Intergovernamental de Mudanças Climáticas AR5 (IPCC, 2014). A elevação média da temperatura entre 1880 e 2012 foi de $0,85^{\circ} \mathrm{C}$. Um aumento substancial que muda o clima do planeta e impacta sobre os ecossistemas terrestres e marinhos, os recursos hídricos e alimentares e a vida humana em geral. Conforme o IPCC (2014), 
se as previsões se confirmarem e os padrões atuais permanecerem, até o fim do século, a temperatura aumentará em até $4^{\circ} \mathrm{C}$. Um aumento tão severo colocaria em risco a população, a segurança alimentar e hídrica do planeta, podendo resultar em extinção de espécies e territórios. Com as mudanças climáticas, eventos que raramente aconteciam ocorrem com mais frequência e intensidade. Outros que nunca ocorriam passaram a acontecer.

Como exemplos locais, o furacão Catarina, ocorrido em Santa Catarina em 2004 (MARCELINO, 2005) e o Ciclone-Bomba ocorrido em 2020 em vários estados do Sul (SOUZA, 2020). Como exemplos globais, o tsunami no Japão, ocorrido em 2011, e a recente pandemia da COVID-19, um desastre biológico que infectou e matou milhões de seres humanos no mundo todo (OPAS-OMS, 2020). Um estudo comparativo sobre desastres no Brasil, realizado num período de 22 anos, aponta que "Há um aumento considerável não apenas na frequência e na intensidade, mas também nos impactos gerados causando danos e prejuízos cada vez mais intensos" (UFSC, 2013, p. 4). Dados da Em-Dat (2020) registram, em 1970, uma média de 80 desastres/ano e em 2008, 400 desastres/ano. No Brasil, ocorreram 22.810 desastres entre 1995 e 2014, principalmente nas áreas urbanas da Região Sul, Sudeste e Nordeste do País (CEPED, 2016).

Já é consenso mundial que o impacto dos desastres atinge o modo de vida das pessoas, causando danos e perdas devastadoras às populações e territórios afetados (AMIN e GOLDSTEIN, 2008). Em 1975, foram gastos 5 bilhões de dólares com desastres. Em 2008, 180 bilhões e em 2015, 300 bilhões (ONU, 2015). Justifica-se a preocupação global, a incorporação dos desastres na agenda governamental e os avanços das pesquisas na área. Destarte os avanços, a falta de consenso e as disputas conceituais entre a área social e técnica nos estudos sempre foram acirradas (PERRY e QUARANTELLI, 2005). Em debate, a compreensão dos desastres a partir do campo cognitivo e do campo político. O primeiro, destaca duas formas de abordagem: o paradigma da ameaça (Hazards) e o paradigma da vulnerabilidade (Disasters); O segundo, a oposição entre as medidas de preparação e recuperação e entre a centralidade estatal e a organização comunitária na gestão.

O campo de estudos sobre desastres iniciou em 1920, em Halifax (Canadá), com estudos de Prince, sobre uma explosão causada pela colisão entre dois navios causando a morte de mais de 10 mil pessoas e desabrigando em torno de 25 mil (QUARANTELLI, 1998). Prince concluiu queo evento não prejudicou o desenvolvimento citadino (PRINCE, 1920). Com a Segunda Guerra e os estudos de dos estudos Gilbert White, em 1945, nos Estados Unidos, sobre perdas e danos por enchentes, o campo de pesquisas se estabeleceu (QUARANTELLI, 1978). White buscou provar que as medidas estruturais implantadas pelo governo não diminuíam os danos e prejuízos ao país e inseriu 
a variável humana nas pesquisas. A inserção objetivou verificar como o ser humano perceberia e se ajustaria aos riscos e no que esse ajustamento implicaria nas políticas públicas adotadas (WHITE, 1973). Com a inserção, áreas de risco e a percepção da população passaram a ser consideradas nos estudos.

A relação homem/meio social e natureza passa a ser o centro das pesquisas sobre desastres (MARANDOLA e HOGAN, 2004). Em 1956, White inseriu secas, furacões e outros fenômenos em seus estudos. A inclusão, abriu o campo de estudos denominado Hazards (perigo ou ameaça) que White (1973) definiu como sendo a interação entre indivíduos e natureza a partir do ajustamento desses aos eventos. Entra em foco a dimensão física e social dos eventos. Surgiu um novo campo de estudos, a abordagem sociológica dos Disasters que considera o contexto social do evento, a população e o impacto deste sobre ela. Considera-se a dimensão física e social dos desastres com ênfase na dimensão social (MATTEDI e BUTZKE, 2001) e ganham importância o agente deflagrador do evento, o agente receptor do impacto e a resposta dada ao impacto. Wenger (1978) vê uma relação intrínseca entre a frequência do evento, o seu potencial de destruição, como ocorre o impacto e a capacidade social de gestão e resposta.

Significa que a resposta não depende apenas do processo geofísico do desastre, mas também da percepção e opinião dos impactados por ele. Também que, quanto menor o período de preparação pré-impacto (Tempo 1) do desastre, maior a destruição no pós-impacto (Tempo 2) (QUARANTELLI e DYNES, 1977). A destruição no Tempo 2 do evento, explicita as condições sociais existentes no Tempo 1. Incorpora-se nos estudos, em 1970, a noção de vulnerabilidade (GALL et al., 2015) e inicia-se um novo campo de estudos sobre desastres. É uma mudança radical na forma de se pensar as relações entre sociedade/natureza e a elaboração e implantação de estratégias de gestão (MARANDOLA e HOGAN, 2004; CARMO e VALENCIO, 2014). A inclusão contribuiu na formulação e implantação de políticas públicas e ações governamentais e na institucionalização das pesquisas e produção científica na área (QUARANTELLI e DYNES, 1977).

Desastres são um problema global, mas se materializam localmente. A forma como se materializam no Brasil é diferente do Japão em função da variação dos contextos físicos e sociais. Destarte, o desafio de estudos comparativos que considerem a vulnerabilidade das populações e territórios, o impacto dos desastres e possibilitem analisar e avaliar a gestão dos desastres e as formas organizacionais de enfrentamento da problemática em nível global, regional e local. Neste sentido, este artigo de cunho qualitativo, bibliográfico e exploratório, apresenta um modelo de estratégias analíticas/ metodológicas em estudos comparativos nos desastres com a finalidade de ratificar a 
utilização da comparação como instrumento de pesquisa nestes campos. O texto não discute diretamente o tema dos desastres, mas trata da metodologia da pesquisa comparativa neste campo de estudos e nas Ciências Sociais. A metodologia foi aplicada na pesquisa sobre 'a gestão dos desastres no Brasil com base no estudo comparativo de casos das secas no Piauí, queimadas em Rondônia e enchentes em Santa Catarina' ${ }^{1}$ desenvolvida no âmbito do Programa de Pós-Graduação em Desenvolvimento Regional da Universidade Regional de Blumenau, Santa Catarina, Brasil.

Esta pesquisa, investigou as relações entre desenvolvimento regional e território, como são produzidos e se reproduzem os desastres, risco e vulnerabilidade. Estudou a Defesa Civil no mundo e no Brasil, procedimentos de gestão, padrão de organização e atuação, em três estados diferentes, diante de três fenômenos distintos, a saber, as secas no Piauí, as queimadas em Rondônia e as enchentes em Santa Catarina. As pesquisas resultaram na produção de artigos para periódicos e na criação de um banco de dados que serviu de subsídio para a tese de doutorado da segunda autora deste texto, estudos futuros e produção científica na área dos desastres. Para fins deste artigo, focou-se nas estratégias analíticas/metodológicas da pesquisa que se utilizou do estudo comparativo como método de trabalho. Os autores objetivam, neste artigo, ratificar a utilização da comparação como instrumento de pesquisa no campo dos desastres e das Ciências Sociais.

\section{O estudo comparativo nas Ciências Sociais}

O estudo dos desastres tornou-se em um campo relevante nas Ciências Sociais no mundo e no Brasil. "O primeiro estudo sistemático sobre desastres foi desenvolvido em 1917 pelo sociólogo canadense Samuel Prince" que estudou a explosão entre dois navios em Halifax, como citado (MARCHEZINI, 2018, p. 45). No entanto, os registros do início do campo de estudos datam de 1950, e hoje passam pela necessidade de amadurecimento afirma Quarantelli (2015). Esse amadurecimento tem critérios. Segundo o autor, "O início do amadurecimento de um campo é marcado pelo desenvolvimento de quadros analíticos ou [...] teorias, modelos, esquemas e hipóteses", afirma (QUARANTELLI, 2015, p. 26). O autor cita nominalmente pesquisadores que já avançaram nesta direção como Barton, Dombrowsky e Perry, precursores na abordagem

1 Apoio da Fundação de Amparo à Pesquisa e Inovação do Estado de Santa Catarina (FAPESP), Edital No 06/2017 - apoio a grupos de pesquisa das instituições do sistema ACAFE. Protocolo EFAP 1435183. Parecer Comitê de Ética no 3.472.193, de 26/07/2019. 
sociológica dos desastres, juntamente com o próprio Quarantelli, considerado o pioneiro dos estudos na área.

No Brasil, durante muito tempo, conforme Valencio et al. (2009), o campo de estudos sobre desastres não tinha muito espaço nas discussões acadêmicas no país. No entanto, com o passar dos anos, no campo das Ciências Sociais, foram surgindo discussões associadas às questões ambientais, à pobreza e às mudanças climáticas. Segundo os autores, essa inserção foi criando a "possibilidade de constituição de uma arena de debates não apenas sob as perspectivas de riscos que a literatura sociológica internacional traz, mas sobre a contribuição nacional para analisar as especificidades dos desastres que pululam no cotidiano de nosso país" (VALENCIO et al., 2009, p. XIII). Hoje, a mobilização das Ciências Sociais para a pesquisa sobre desastres socioambientais é um campo importante e necessário no estudo dos fenômenos no país. Principalmente no que tange as contribuições que podem advir das disciplinas que compõe a área para este campo de estudo. Ou seja,

[...] a aplicação dos estudos e análises das Ciências Sociais contribuem para o direcionamento da elaboração de políticas públicas voltadas à redução [...] da vulnerabilidade a desastres, com ações integradas entre as instituições e a sociedade (MARCHEZINI apud CEMADEN, 2018, S/P).

A interpretação dos desastres no campo da Sociologia, por exemplo, para Valencio et al. (2009), é de suma importância e hoje se apresenta profícua, após algum tempo de silêncio. Mesmo a falta de consenso e disputas conceituais entre a área social e técnica no estudo dos desastres (PERRY e QUARANTELLI, 2005), para os autores, existem aspectos em comum. Um desses aspectos é que não há centralidade nos estudos de variáveis independentes relacionadas de forma intrínseca com os fenômenos naturais. Conforme Valencio et al. (2009, p. 5), “A compreensão dos desastres para a Sociologia focaliza centralmente a estrutura e dinâmica social que, num âmbito multidimensional e multiescalar, dá ensejo a variadas interpretações acerca das relações sociais territorial, institucional e historicamente produzidas". A abordagem sociológica foca na dimensão natural e na dimensão social dos desastres com ênfase na dimensão social, como visto.

No entanto, apesar dos avanços, em relação às outras áreas de estudo do contexto brasileiro, o debate nas Ciências Sociais ainda é incipiente e carece de processos de reflexividade, segundo Valencio (2009) e Marchezini (2018). Tanto de parte das instituições públicas, como das próprias Ciências Sociais, "cujo sentido é de, entre outros, colocarem-se em permanente construção de interpretações do mundo contemporâneo, no qual estas ciências estão indelevelmente situadas" (VALENCIO et al., 2009, p. 5). Para Marchezini (2018), o estudo dos desastres nas Ciências Sociais é uma área ainda 
em construção, mas extremamente necessária para os processos de desnaturalização dos desastres. Segundo afirma:

De forma crítica, são necessários empenho e colaboração para desnaturalizar o desastre denominado 'natural'. Precisamos de pesquisas sobre as causas básicas dos desastres e as pressões dinâmicas que colaboram para a construção social do risco de um desastre (MARCHEZINI, 2018, p. 61, grifo no original).

A participação das Ciências Sociais no estudo dos desastres, segundo Marchezini (2018), tem sido citada em fóruns multilaterais, plataformas globais e artigos científicos. Aos poucos os desastres começam a fazer parte da agenda de estudos, pesquisas e produção científica da área. Em seu artigo, As Ciências Sociais e os desastres: um campo de pesquisa em construção, Marchezini (2018) ratifica a escassez de estudos e produção científica nas Ciências Sociais, mas também apresenta teses e dissertações que tratam da temática em suas várias abordagens e salienta, citando Lavell (2005) e Valencio (2017), que "seria frutífero reunir esforços para uma agenda de pesquisa no tema, [...] além de pôr em debate metodologias e formas de relacionar-se com outras ciências" (MARCHEZINI, 2018, p, 62). O autor ratifica a atenção crescente das Ciências Sociais para o estudo do tema dos desastres e os avanços para o debate metodológico.

No que tange ao debate metodológico, este item propõe discutir o estudo comparativo nas Ciências Sociais. Como premissa, a ideia de que os estudos comparativos permitem conhecer aspectos macro e microssociais nos procedimentos investigativos tanto nas Ciências Sociais, como em outras áreas. Bereday (1998) salienta que a comparação não é pura e simplesmente um método. $\mathrm{O}$ autor entende a comparação como uma ciência que tem como objeto "deslindar as semelhanças e diferenças dos sistemas" ou fenômenos que compara (BEREDAY, 1998, p. 12). Significa que, para o autor, o estudo comparativo explicita, torna inteligível, compreensível o que antes estava escondido, obscuro, confuso e firma-se como um importante instrumento de investigação, conhecimento, compreensão e análise da realidade (SILVA, 2016). Firma-se, também, como estratégia de possíveis contribuições e melhorias resultantes dos resultados apresentados. Não quer dizer, que

[...] siempre que se compare se haga siguiendo unos procedimientos científicos. Para que esto ocurra se tienen que dar los siguientes pasos, presentados de una manera breve y general: determinar los objetos a comparar; en qué aspectos son comparables y, además, seguir unas estrategias de análisis para llegar a unas conclusiones (ROMERO e FERNÁNDES, 2009, p. 413).

Na literatura sociológica, segundo Marshall (1998), existem duas orientações gerais de análise comparativa, já citadas por Bereday (1998). Existem estudos que buscam 
similaridades e outros que primam pela singularidade. No que tange aos que buscam similaridades, o autor coloca que esta, à luz de alguma teoria, é colocada à prova em diferentes contextos históricos e sociais. Quanto as singularidades, estas enfatizam especificidades, rejeitam a busca por teorias gerais, regras ou leis e utilizam a pesquisa comparativa para esclarecer as diferenças com o objetivo de, a partir delas, entender arranjos e especificidades sociais encontradas. Significa que o estudo comparativo pode contribuir muito para o campo de estudos das Ciências Sociais dadas as especificidades de sua proposta investigativa. Bem como, à possibilidade de se comparar diferentes contextos e distintas realidades a partir do método das semelhanças e diferenças.

Conforme Franco (2000) o método comparativo tem origem no desenvolvimento da sociologia a partir das contribuições de Durkheim e Weber. Ambos, juntamente com Comte, utilizaram o método como instrumento de explicação e generalização, segundo Schneider e Schmitt (1998). Se o método do estudo comparativo surgiu na sociologia, a antropologia foi a ciência que, segundo Franco (2000), colocou em discussão "o outro" e valorizou a diferença, a diversidade e o papel dessas categorias na história da espécie. E, segundo Woortman (s/d), devido a isso, e por utilizar o método desde os primórdios, a antropologia é considerada por alguns estudiosos como o ponto de vista comparativo. No entanto, é a John Stuart Mill que se deve em grande parte, em 1881, ainda antes de Durkheim, a concepção do método. Na época, o estudioso trabalhou com duas possibilidades de aplicação da comparação: a concordância e a diferença (GONZALEZ, 2008).

A partir de Mill, o estudo comparativo se fundamenta no método das semelhanças e das diferenças ou ainda na observação das diversas variáveis concomitantes a elas (SANTOS, 2012). É, também, o método que pode utilizar estudos de casos como estratégia de investigação, além de privilegiar analogias ou contrastes e estabelecer correlações entre o objeto estudado a partir dos casos. Para Bendix (1977), os estudos comparativos ampliam a visibilidade de uma estrutura ou sistema em contraste com a outra e segundo Silva e Barros (2011, p. 2), contribuem muito "para a própria consolidação das Ciências Sociais em seus vários campos temáticos". Segundo os autores, os modos de comparação podem ser diversos, dependendo da demanda. Salientam a diversidade dos objetos de estudo que tanto podem ser "processos e períodos, como países, grandes regiões ou pequenas comunidades; políticas e instituições; grupos e movimentos, ou ainda culturas, valores e representações" (SILVA e BARROS, 2011, p. 2).

Segundo afirmam os autores, 
O empreendimento da comparação também pode variar em escala e dimensão, estar embasado em maior ou menor referência histórica; se reportar a aspectos quantitativos ou qualitativos e mesclar ambos; explorar semelhanças e diferenças, e até enfrentar o desafio de uma construção interdisciplinar, a partir de convergências e intersecções entre a Sociologia, a Antropologia e a Ciência Política (SILVA e BARROS, 2011, p. 2).

A importância do exercício de análise de algumas das diversas possibilidades da prática comparativa vai ganhando espaço nos centros de pesquisa e programas de pós-graduação das Ciências Sociais, onde o método comparativo é explorado como requisito em linhas de estudos e pesquisas (SILVA e BARROS, 2011). Ou seja, "a pesquisa comparativa nas Ciências Sociais constitui-se numa ferramenta poderosa de análise", no entanto, seu objetivo "não é comparar, mas vislumbrar as possíveis implicações a partir da comparação" (SILVA e BARROS, 2011, p. 5). Significa que o método comparativo pode chegar aonde outros instrumentos de investigação tem dificuldades, pois não inventa semelhanças "fictícias", mas descobre semelhanças "in re" (SARTORI, 1997). Significa que mesmo que duas coisas ou mais não sejam comparáveis e sejam subentendidas como heterogêneas, a comparabilidade leva à homogeneidade e é a não-comparabilidade que se associa à heterogeneidade (SARTORI, 1997).

Ou seja, mesmo que o estudo comparativo utilize a comparação a partir das semelhanças e diferenças, não é a comparação que é analisada no estudo, mas o objeto de investigação desta. Conforme Badie e Hermet (1993), não importa se os objetos comparados pertençam a contextos sociais diferentes e distantes, importa que estes sejam comparáveis. Para isso, é necessário que pertençam a uma mesma categoria, como por exemplo países, estados ou leis, e que possuam pontos em comuns que permitam a comparação e esta seja validada. Para Sartori e Mornilo (2002), a comparação é inútil em casos em que os objetos da comparação são totalmente iguais ou totalmente diferentes. Mas, deve ocorrer em casos em que os objetos a serem comparados possuem atributos comparáveis (pontos similares) e não comparáveis (pontos diferentes, incomparáveis) e possam ser esclarecidos os aspectos particulares, as especificidades de cada caso individual.

Conforme Schneider e Schmidt (1998) três dimensões devem ser consideradas na aplicabilidade dos estudos comparativos: 1) a seleção de duas ou mais séries de fenômenos que sejam efetivamente comparáveis entre si; 2) a definição dos elementos comparáveis (como temas ou categorias, por exemplo); e 3) a generalização. Significa que os estudos comparativos primam por uma forma controlada de questionamento, investigação e aproximação organizada que possibilita o proceder científico (WOORTMAN, $s / d)$ a partir das similitudes e dissimilitudes do objeto em estudo. Para Pronko (s/d), o 
método da comparação ainda tem gerado, no âmbito das Ciências Sociais, “importantes debates de corte metodológico, epistemológico e prático". No entanto, na opinião do autor, o estudo comparativo já tem sido explorado na área em seus mais diversos contextos. Destarte a necessidade de se avançar na discussão, tanto na área das Ciências Sociais, como no campo dos desastres.

\section{O estudo comparativo no campo dos desastres}

No Brasil, estudos comparativos no campo dos desastres não são tão comuns na literatura atual. Em nível mundial, encontrou-se em Marchezini (2018) registros de que nas Ciências Sociais o primeiro estudo sistemático sobre desastres foi desenvolvido pelo canadense Prince, como citado. O autor relata que, em 1942, o sociólogo russo Pitirim Sorokin buscou analisar as principais normalidades manifestadas em períodos de calamidades como fome, doenças, guerras etc. Na antropologia, o autor cita dois trabalhos realizados na década de 1950: os estudos, de cunho descritivo, dos antropólogos “Cyril Belshaw e Felix Keesing, que analisaram a organização social e as formas de adaptação do povo Orokaiva ao desastre ocorrido após a erupção do Monte Lamington em Papua Nova Guiné" (MARCHEZINI, 2018, p. 46). Bem como, os estudos de Raymond Firth, que analisou o comportamento do povo Tikopian em tempos de fome subsequente a dois ciclones ocorridos na Polinésia.

Marchezini (2018) cita ainda outros estudos no campo perceptivo e comportamental em eventos críticos e a criação dos primeiros centros de pesquisa na área dos desastres, como o Disaster Research Center (DRC), em Ohio (EUA), criado em 1963. Antes disso, ainda no âmbito da antropologia, Faas e Barrios (2015) citam os estudos de Anthony Wallace que, em 1956, desenvolveu um modelo analítico que permitia o estudo comparativo de casos. Segundo os autores, o antropólogo pesquisou as mudanças na personalidade e na saúde mental das pessoas em casos de estresse como os causados por calamidades. Em seus estudos, considerou desastres como processos cuja dimensionalidade espaço-temporal lhe permitia investigar as mudanças culturais e como estas poderiam ser catalisadas por catástrofes (FAAS e BARRIOS, 2015; MARCHEZINI, 2018). Considera-se, conforme Marchezini (2018) este o primeiro estudo comparativo no campo dos desastres que se tem registro.

Quarantelli (2015), apresenta diversos estudos comparativos no campo dos desastres. Um desses, comparou o comportamento em desastres naturais/tecnológicos e o comportamento em motins e manifestações civis violentas nos Estados Unidos (QUARANTELLI, 1993). Importante citar que não foram os eventos, diferentes entre si, que 
foram comparados, mas o comportamento diante deles. A comparação ocorreu nos "níveis individual, organizacional e comunitário nos estágios de pré-impacto, impacto e pós-impacto, de ambos os tipos de ocasiões" (QUARANTELLI, 2015, p. 34). Os resultados explicitaram semelhanças de comportamento e inúmeras diferenças, algumas marcantes, especialmente no nível organizacional. E apontaram que, em caso de desastres, os indivíduos reagem de forma ativa e pró-social, sendo que nos motins ocorre mais variabilidade comportamental, com evidente comportamento antissocial.

Além disso, enquanto a experiência de um desastre pode ser dita como memorável, e há diferentes tipos de efeitos, parece não haver muitas consequências comportamentais de longa duração entre os sobreviventes; já os motins parecem deixar mais consequências. Similarmente, há de alguma forma mais probabilidade de haver mudanças organizacionais após os motins do que após os desastres. No nível da comunidade, desastres envolvem significativo comportamento de convergência de pessoas e grupos; o que é muito menos verdadeiro no caso dos motins. Embora existam resultados seletivos e mudanças nas comunidades afetadas pela crise, o impacto é menor em desastres típicos do que em motins (QUARANTELLI, 2015, p. 35).

O estudo em questão corrobora com Badie e Hermet (1993), Sartori e Mornilo (2002), quando afirmam que o objeto dos estudos comparativos pode pertencer a contextos sociais diferentes e distantes, mas que necessitam possuir atributos, categorias ou pontos em comum que permitam a comparação entre eles. Os estudos comparativos nos desastres podem contribuir nas estratégias de investigação sobre o impacto dos desastres sobre diferentes contextos sociais, sobre as dinâmicas de enfrentamento e as relações institucionais e de configuração organizacional que procedem ao impacto. $\mathrm{O}$ processo comparativo possui três fases, conforme explicita a Figura 1: 1) a investigação do impacto; 2) o isolamento das variáveis; e 3) as semelhanças e diferenças entre os objetos comparados. $\mathrm{O}$ método permite esclarecer aspectos particulares e individuais dos casos e pode se utilizar tanto de variáveis quantitativas como de categorias qualitativas. No entanto, conforme Richardson (1989), os procedimentos qualitativos são adequados à busca dos fenômenos enquanto processos dinâmicos. 


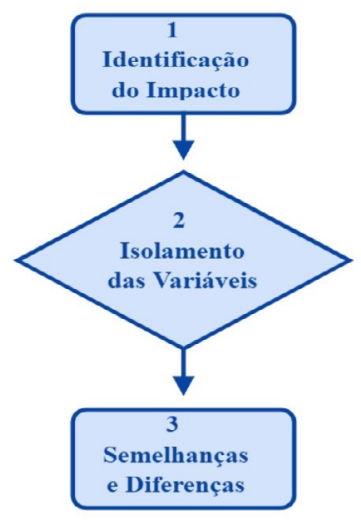

Figura 1: Fases do estudo comparativo no campo dos desastres

Fonte: Elaboração dos autores (2020)

Neste sentido, a análise comparativa permite a ampliação da abrangência da investigação, melhorando a compreensão por meio do aprofundamento e do foco no todo do objeto investigado. Permite também a investigação dos sistemas inter-relacionados aos fenômenos, ou seja, amplia o contexto da investigação explicando as conexões existentes entre esse e o evento ocorrido. Isso ficou evidente no exemplo de estudo comparativo apresentado por Quarantelli (2015). Outro estudo apresentado pelo autor, apontou que terremotos de uma magnitude aproximada podem ter efeitos sociais negativos diferentes. Trata-se do estudo comparativo entre os terremotos ocorridos em Loma Prieta (Califórnia) e na Armênia. No primeiro caso, as mortes e destruição constatadas nos resultados representaram apenas uma pequena fração das que ocorreram no segundo. No entanto, em termos de magnitude, ambos os eventos se equipararam (QUARANTELLI, 2015).

O estudo apresentado evidencia a importância dos estudos comparativos, bem como, "a visão dos estudiosos em ciência social que preconizam que todos os desastres são essencialmente o resultado das ações humanas" (QUARANTELLI, 2015, p. 40) ratificando a abordagem sociológica dos desastres que enfatiza a dimensão social dos eventos e considera a noção da vulnerabilidade. Neste sentido, evidencia-se a importância de se considerar a mudança recente na literatura, de um foco principal no risco, para um foco na vulnerabilidade, na abordagem dos desastres. Para Quarantelli (2015) um desastre não é um evento físico, mas social. $O$ autor entende que hoje não é mais apropriado falar em desastres "naturais", pois estes não existem fora das ações e decisões dos seres humanos e suas sociedades. E cita como exemplos as inundações, 
terremotos e outros eventos, chamados de "agentes naturais" que têm consequências sociais pós-impacto exclusivamente

[...] por causa das atividades desenvolvidas pelas comunidades antes, durante e após o impacto de um desastre. Permitir altas concentrações de densidade populacional em planícies de inundação, construir estruturas não resistentes ou não reforçadas contra terremotos, permitir habitação em encostas vulcânicas, fornecer informação ou sinal de alerta inadequados em caso de tsunamis, por exemplo, constituem casos mais graves do que o agente do desastre em si, pois causa vítimas, perdas econômicas e patrimoniais, tensão psicológica e interrupção de atividades cotidianas que são a essência dos desastres. As características das ocasiões de desastre do passado, do presente e do futuro se originam a partir de fatores sociais (QUARANTELLI, 2015, p. 41, grifo no original).

Significa que um mesmo evento pode ter impactos diferentes dada a vulnerabilidade dos territórios e populações atingidas. Conforme Anderson (1995), os desastres têm impactos diferenciados sobre as populações que vivem em áreas de risco. Ou seja, perdas de vida, saúde e bens variam "muito entre as pessoas que vivenciam o mesmo desastre e entre pessoas que vivenciam desastres do mesmo tipo e da mesma proporção em momentos diferentes e em diferentes partes do mundo" (ANDERSON, 1995, p. 45). Neste sentido, o foco dos efeitos dos desastres não se encontra mais nas vítimas e nos danos e perdas por desastres, mas na pergunta sobre em que medida o desastre reflete aspectos nocivos de processos sociais contínuos. Ou seja, o impacto pós-desastre é explicado pela estrutura e as dinâmicas do sistema social pré-desastre (ALBALA-BERTRAND, 1993; MATTEDI, 1999). Destarte a importância de estudos comparativos na área.

O método comparativo pode ser utilizado para estudar o impacto dos desastres sobre territórios e populações, a gestão dos desastres e as formas organizacionais de enfrentamento da problemática em nível global, regional e local etc. É diverso e profícuo o campo investigativo na área. O antigo Ministério da Integração (2003), hoje denominado Ministério em Desenvolvimento Regional, também recomenda o estudo comparativo no campo dos desastres em várias áreas, como a gestão, a prevenção etc. Ao tratar dos sistemas de monitoramento, alerta e alarme em desastres, o Manual de Desastres Humanos (MI, 2003) enfatiza a importância da observação, do registro, da medição, da comparação e da avaliação repetitiva e continuada de dados técnicos e de parâmetros de funcionamento, a partir de esquemas pré-estabelecidos, no tempo e no espaço utilizando métodos comparativos. A utilização da comparação tem como finalidade principal 
- estudar todas as variáveis presentes no fenômeno ou processo de observação;

- identificar os parâmetros de normalidade e, a partir da definição dos mesmos, alertar, em tempo real, sobre possíveis desvios significativos do processo;

- facilitar a tomada de decisões e permitir a articulação de respostas coerentes e oportunas, com o objetivo de bloquear sequências de incidentes e restabelecer as condições de normalidade, no mais curto prazo possível; - articular respostas sistêmicas adequadas, em interação com os demais sistemas de segurança e de alívio (MI, 2003, p. 345).

Conforme Dynes (1971, p 1), poucas pessoas têm interesse no estudo comparativo em desastres e alguns pesquisadores até militam contra, no entanto "os desastres podem fornecer oportunidades excepcionais para a análise comparativa dos sistemas sociais uma vez que ativam uma variedade de estruturas e processos com que o sistema social tenta lidar e que em tempos normais surgem mais lenta e segmentalmente". Para o autor, essa complexidade que se explicita em estudos comparativos, é frequentemente minimizada em outros métodos de pesquisa, uma vez que as metodologias são utilizadas para investigações mais abstratas, ao invés de se estudar as complexidades das inter-relações sociais em desastres. Os estudos comparativos, segundo Dynes (1971), não são usados apenas para a compreensão da adaptação mais imediata dos sistemas sociais aos impactos dos desastres, mas também porque eles são significativos na compreensão da mudança social provocada por eles a longo prazo.

Dynes (1971) cita alguns estudos destacando as pesquisas de Clifford (1956) que comparou as diferentes respostas de duas comunidades diante de uma mesma inundação. Uma das comunidades localizava-se no México e outra nos Estados Unidos. O pesquisador descobriu que a comunidade mexicana tinha mais dependência do grupo de parentesco como fonte de conselho e ajuda do que a americana. Havia uma maior relutância em aceitar ajuda, maior resistência de cooperação entre as agências relacionadas a desastres e uma tendência maior em depender de uma liderança personalizada "heroica" ao invés da autoridade "racional" e da cooperação. Em outro estudo, Luckie (1970) analisou a resposta ao impacto dos desastres de três comunidades localizadas em três países distintos: Japão, Itália e Estados Unidos. Destarte a localização, as três eram "semelhantes em uma série de variáveis demográficas, econômicas e políticas" (DYNES, 1971, p. 3) e estavam sujeitas a desastres semelhantes que se diferenciavam apenas por serem mais ou menos centralizados.

Após combinar tantas variáveis, Luckie (1970) observou as consequências da centralização política do poder decisório no desempenho das ações em desastre. Houve indícios de que nas formas mais centralizadas de ações preventivas, envolvendo evacuação, esta foi frequentemente mais lenta. Luckie (1970) concluiu que “a centralização das decisões nas autoridades políticas mais altas pode tornar difícil para funcionários locais 
tomarem decisões embora tenham uma avaliação mais realista da situação" (DYNES, 1971 , p. 3) e que os responsáveis pelas ações que teriam prioridade imediata para fazer escolhas tendem a fazer uma tomada de decisão menos centralizada, independentemente da estrutura. O grau de centralização da decisão variou ao longo da sequência de tempo do evento, bem como o seu efeito. Conforme Dynes (1971), houve a tendência deste grau de centralização ser minimizado nas fases iniciais do impacto, quando as ações de alta prioridade estavam envolvidas, mas sua importância foi reafirmada no último estágio da atividade do desastre.

Dynes (1971) cita vários estudos comparativos nos desastres e frisa a importância destes nas pesquisas na área. A aplicação do estudo comparativo no campo dos desastres é um desafio contemporâneo nas Ciências Sociais e em outras áreas do conhecimento como a "geografia, psicologia, economia [...] comunicação, administração pública [...] meteorologia, engenharias etc." (MARCHEZINI, 2018, p. 47). No que tange à aplicabilidade, o estudo comparativo requer cuidados na definição de todos os passos ou procedimentos investigativos. Conforme Bulgacov (1998), esse cuidado passa pela definição do problema, das variáveis ou categorias envolvidas, do universo e seus critérios de definição, da fundamentação teórica-empírica, da metodologia e procedimentos de levantamento de dados e das técnicas ou instrumentos de coleta de dados. Esse cuidado se mostra imprescindível para a validação das estratégias analíticas/metodológicas em estudos comparativos no campo dos desastres.

\section{Estratégias analíticas/metodológicas em estudos comparativos no campo dos desastres}

A desnaturalização dos desastres implica em mudanças de paradigmas. É uma guinada no marco referencial na forma de compreender e gerir a problemática. Em 1994, em Yokohama foram elaboradas estratégias de redução de desastres, mas foi com o Marco de Ação de Hyogo ocorrido em 2005 e o Marco de Sendai (marco vigente) que as estratégias para uma mudança total de paradigmas foram estabelecidas (ONU, 2015). Ao invés da Gestão de Desastres (GD), passa a ser adotada a Gestão de Risco de Desastres (GRD), tendo como órgão responsável a Defesa Civil. A instituição é o objeto de estudo do modelo de estratégia analítica/metodológica em estudos comparativos no campo dos desastres, a ser apresentado neste item. A pesquisa em questão, teve como objetivo 
geral 'investigar a gestão dos desastres no Brasil com base no estudo comparativo das secas no Piauí, queimadas em Rondônia e enchentes em Santa Catarina'.

Os três fenômenos citados impactam sobre populações e territórios, demandando agilidade nos processos de decisões políticas e ações governamentais de enfrentamento às situações de emergência. Uma ação governamental, conforme Mattedi (1999) e Bohn et al. (2012), possui vínculos estabelecidos entre a dimensão externa e a dimensão interna. Na externa, destacam-se os processos de representação de interesses, tais como os dos grupos políticos. Estes podem ser mais ou menos integrados. São mais integrados quando as elites determinam as demandas, e menos integrados quando a sociedade organizada participa na formação das demandas. Na dimensão interna são os procedimentos políticos institucionais de decisão (leis) que se sobressaem. Estes podem ser mais ou menos centralizados. São mais centralizados quando há concentração das decisões no Governo central e menos centralizados quando há capacidade decisória no Governo local.

No Brasil, o processo decisório da gestão dos desastres se dá em três níveis: nacional, estadual e municipal e é operacionalizado pela Defesa Civil. A preocupação com a forma de gerir os desastres no país originou reflexões que questionaram a Defesa Civil no Brasil e se a sociedade organizada participava da gestão. As perguntas geraram um projeto de pesquisa, no âmbito do Programa de Pós-Graduação em Desenvolvimento Regional da Universidade Regional de Blumenau, com a proposta de analisar a gestão de desastres, operacionalizada no país pela Defesa Civil, com base no estudo comparativo de casos das secas no Piauí, queimadas em Rondônia e enchentes em Santa Catarina. Como hipótese, a conclusão de que a Defesa Civil possui caráter centralizador, burocrático e militar e atua protocolarmente diante de diferentes fenômenos e regiões sem considerar as especificidades de cada região ou fenômeno e a participação da sociedade na gestão.

O objeto de análise foi a gestão e não os estados ou fenômenos. Um mesmo sistema presente em três estados diferentes, com a preponderância de ocorrência de tipos diferentes de fenômenos. Portanto, é a Defesa Civil de cada uma das unidades federativas que teve suas ações analisadas. E é a partir do estudo comparativo da atuação da instituição nos três estados que se instituiu parâmetros para compreender a gestão no Brasil. Isto corrobora com o pensamento de Badie e Hermet (1993), Sartori e Mornilo (2002), quando tecem afirmações de que o objeto dos estudos comparativos pode pertencer a contextos diferentes, mas comparáveis. A escolha dos referidos estados a serem pesquisados ocorreu por fatores importantes para um estudo comparativo: 
os três localizam-se em macrorregiões bem distintas entre si, tem preponderância de diferentes fenômenos e, juntos, formam uma triangulação geográfica no mapa do país.

A escolha do estudo comparativo com base na estratégia investigativa do estudo de casos ocorreu porque o método permitiu destacar as diferenças e peculiaridades dos referidos casos gerando resultados em nível específico que resultaram num modelo para a análise em nível geral. Também, pelos pontos levantados anteriormente sobre estudos comparativos nas Ciências Sociais e no campo dos desastres. As estratégias analíticas / metodológicas deste estudo comparativo nos desastres são aqui explicitadas para ratificar a importância da utilização da comparação neste campo. O desenvolvimento da pesquisa fundamentou-se metodologicamente na abordagem qualitativa (MINAYO, 2014) de finalidade teórico/empírica porque se utilizou da teoria para o desvelamento da realidade estudada, numa relação dialética, num movimento de ir e vir do conhecimento científico, saberes locais/regionais, bem como da produção de dados em campo.

A pesquisa não possui um fim conclusivo, mas exploratório (BEUREN, 2004; CRESWELL, 2010). Levantamento preliminar do estado da arte apontou que são raros os estudos no viés proposto e que estudos comparativos sobre a gestão dos desastres com foco na Defesa Civil e sociedade organizada ainda são pouco explorados na área dos desastres socioambientais. Neste sentido, os resultados finais poderão agregar novos conhecimentos ao acervo que ainda se mostra escasso. Uma das estratégias de investigação dos estudos comparativos é o estudo de caso. Conforme Yin (2001), nos estudos de caso os dados são buscados em profundidade e podem evidenciar singularidades, semelhanças e diferenças entre as situações estudadas. Por se tratar de um estudo comparativo de caso com caráter exploratório, foram escolhidas técnicas adequadas para a coleta de dados: a revisão bibliográfica, pesquisa documental em leis etc. a pesquisa empírica ou de campo.

As informações foram colhidas por meio da entrevista aberta e semiestruturada (SAUNDERS, LEWIS e THORNHILL, 2012), com roteiro previamente elaborado para guiar a entrevista e manter a abordagem no objeto da pesquisa. Essas perguntas iniciais e abertas permitiram aos entrevistados relatarem pensamentos, vivências e experiências em relação aos fenômenos específicos e sobre a Defesa Civil. As entrevistas foram gravadas, transcritas para posterior análise e tratamento, e foram anexadas ao banco de dados do grupo de pesquisa coordenado pelo autor principal deste artigo. Os entrevistados assinaram Termo de Consentimento Livre e Esclarecido (TCLE) autorizando o uso das informações fornecidas. A liberação da pesquisa empírica se deu por meio 
de assinatura do Formulário de Solicitação e Realização de Pesquisa Empírica (FAPE) pelos representantes de universidades parceiras e Defesa Civil estadual².

No que tange ao universo e à amostra, por ser uma pesquisa qualitativa que se preocupa com os estudos em profundidade, esta foi selecionada de forma não probabilística (BABBIE, 1990; SAUNDERS; LEWIS e THORNHIL, 2012). Quando contatados, os próprios entrevistados indicaram outros para possíveis entrevistas. Essa estratégia é conhecida como sendo do tipo bola de neve - snowball sample (BABBIE e MOUTON, 2001). O perfil dos 35 entrevistados é composto pelos Setores Especializado, Governamental e da Sociedade Organizada.

A pesquisa foi dividida em etapas. A primeira, visou o aprofundamento sobre eixos de aportes teóricos: Desastres; Desenvolvimento Regional + Território; e Gestão. Estudou-se os processos de ocupação e desenvolvimento dos territórios pesquisados, o processo histórico da produção da vulnerabilidade, representações e percepções de risco e vulnerabilidade. Ainda a construção social do território do desastre, concepções e teorias autores e pesquisadores da área.

Na segunda etapa, estudou-se a história da Defesa Civil no mundo e no Brasil e os processos de sua territorialização e institucionalização. Caracterizou-se os Estados e fenômenos relacionados. Investigou-se a conduta e os procedimentos da gestão dos desastres a partir da relação e das características entre os fenômenos das secas, queimadas e enchentes que atingem cada estado, suas especificidades e o que possuem em comum.

\footnotetext{
Na terceira etapa, investigou-se a atuação da Defesa Civil e a sociedade organizada, como se instrumentalizava a Defesa Civil, suas ações no pré, trans e pós-impacto dos desastres. Buscou-se saber se atuavam de forma semelhante - estruturada e preestabelecida - ou de modo particular, de acordo com as especificidades de cada região e fenômeno. Por fim, buscou-se saber se a sociedade organizada participava da gestão. Nesta fase, no período de agosto de 2019 a junho de 2020, foi realizada a pesquisa de campo, com a utilização de entrevistas como técnica de coleta de dados.
}

As entrevistas foram transcritas e os dados distribuídos em categorias por similaridades ou diferenças entre as falas do coletivo pesquisado. As categorias foram elencadas no projeto inicial de pesquisa ou durante a pesquisa empírica que precisou ser flexível para incorporar categorias que emergem da realidade durante o processo de campo.

2 No Piauí, foi realizada parceria com a Universidade Federal do Piauí (UFPI) e em Rondônia com a Universidade Federal de Rondônia (UNIR) - campus de Cacoal. A coordenação da pesquisa centrou-se no Núcleo de Estudos de Tecnociência (NET), grupo de pesquisa do Programa de Pós-Graduação em Desenvolvimento Regional da Universidade Regional de Blumenau. 
As entrevistas foram codificadas com a finalidade de preservação do sigilo dos sujeitos entrevistados. Neste processo foi utilizado o software MAXQDA (2020) que auxilia na análise de dados qualitativos não estruturados. O software fornece área de trabalho e auxílio às etapas, desde a organização até a análise e posterior geração de relatórios facilitando o trabalho do pesquisador. As entrevistas e as leis que regem a Defesa Civil nos estados estudados foram agrupadas por estado, sistematizadas em arquivo individual e introduzidas no software de análise onde receberam identificação e codificação por categorias que tinham referência com o tema em estudo.

A pesquisa tem como base o estudo comparativo de casos, portanto, a análise se deu por triangulação comparativa dos depoimentos à luz do arcabouço teórico/metodológico adotado. O método utilizado permitiu uma comparação tridimensional sobre o que pensam os diversos sujeitos da pesquisa sobre uma mesma categoria analítica. "A triangulação pode combinar métodos e fontes de coleta de dados qualitativos e quantitativos (entrevistas, questionários, observação e notas de campo, documentos)" (AZEVEDO et al., 2013, p. 4). Esse método, pode ainda, combinar "diferentes métodos de análise dos dados: análise de conteúdo, análise de discurso, métodos e técnicas estatísticas descritivas e/ou inferenciais, etc." (AZEVEDO et al., 2013, p. 4). O objetivo da triangulação é contribuir para um olhar sob múltiplas perspectivas e permitir o surgimento de novas e mais profundas dimensões no exame de um mesmo fenômeno ${ }^{3}$. A Figura 2 explicita o processo de análise do estudo em questão.

3 "Vários especialistas ressaltam a conveniência da combinação de métodos, devido às fragilidades encontradas em projetos que empregam um único método. Os principais defensores da estratégia de triangulação - Webb et al. (1966), Smith (1975), Denzin, (1978), Flick (1992) - não indicam como ela realmente deveria ser executada. A maior parte dos cursos de pós-graduação prepara os estudantes para a utilização de um ou outro método, mas não para o emprego combinado de multimétodos. Há necessidade de um estudo mais aprofundado das "técnicas", visando a fornecer detalhes suficientes para explicar com exatidão como os dados convergentes são coletados, analisados e interpretados" (AZEVEDO et al., 2013, p. 2). 


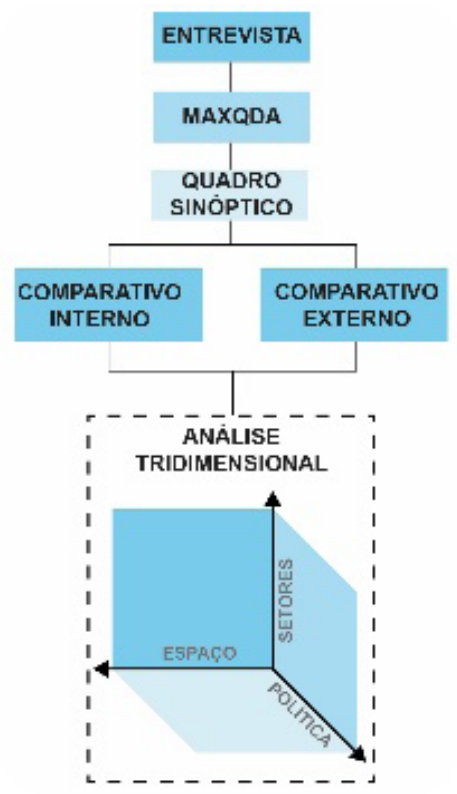

Figura 2: Visualização do processo de análise Fonte: Elaboração dos autores (2020)

A análise, tanto dos conteúdos das leis como dos discursos, permitiu interpretações e interferências mais significativas a partir das categorias. Os dados foram tratados a partir da fundamentação teórica existente. Essa fase é denominada por Bardin (1977) de fase de inferência e interpretação dos dados. Aqui ocorreu a análise comparativa dos dados a partir da perspectiva tridimensional do Espaço (território), Setores (comunidade e especialistas) e da Política (Política Nacional de Proteção e Defesa Civil e Políticas Estaduais de Defesa Civil do Piauí, Rondônia e Santa Catarina). O resultado do estudo das categorias nas leis, entrecruzou-se com o resultado dos discursos dos sujeitos entrevistados, gerando a Análise Comparativa Tridimensional em dois eixos: comparativo externo (leis) e interno (entrevistas).

Os resultados apontaram para uma relação de interdependência entre desenvolvimento socioeconômico e desastres. Esta se caracteriza pela influência do desenvolvimento sobre os desastres e destes sobre o desenvolvimento, intrínseca, mutual e ambivalentemente. Significa que os desastres podem ser considerados indicadores do desenvolvimento regional, permitindo aumentar potencialidades ou aprofundar deficiências e desigualdades sociais do território. Neste sentido, a importância da inclusão da noção de vulnerabilidade no campo de estudos dos desastres, pois quando estes ocorrem e as situações de emergência se instalam, os que mais sofrem são os que reúnem maiores indicadores de vulnerabilidade. São, também, os que mais têm perdas e os que encontram mais dificuldades para a recuperação pós-impacto. Viu-se que o 
processo histórico da produção da vulnerabilidade apresenta padrões globais e regionais condicionados pelos padrões de desenvolvimento socioeconômico dos territórios.

Significa que o enfoque da gestão deve estar em modelos não lineares de gestão que centralizem as ações na noção de vulnerabilidade e na gestão de risco de desastres. Como visto, a instituição responsável pela gestão é a Defesa Civil cuja história no mundo vincula-se as duas primeiras grandes guerras. Na $1^{\text {a }}$ Guerra, foram utilizados balões dirigíveis, deslocando ações de defesa antes focadas nas frentes e retaguardas de batalha para a defesa de ataques pelo ar. $\mathrm{Na} 2^{\mathrm{a}}$ Guerra, os balões foram substituídos por aviões que atacaram territórios urbanos e população civil. A ação de enfrentamento dessa nova forma de fazer guerra foi a criação da primeira instituição de Defesa Civil, a CIVIL DEFENSE, que objetivava proteger e preparar civis e elaborar estratégias de defesa da população e territórios. Com a institucionalização e territorialização da Defesa Civil, os avanços trouxeram mudanças de paradigmas preconizadas nas Conferências de Yokohama, Hyogo e Sendai e premissas de atuação integrada entre governo e população.

Hoje, a Defesa Civil é vista no mundo todo como sendo o conjunto de ações tanto preventivas, como de socorro, assistenciais e reconstrutivas cuja finalidade é dirimir ou minimizar o risco de desastres e restabelecer a normalidade social nos territórios atingidos pelos fenômenos (SEDEC, 2016 [2012]. A pesquisa investigou 18 instituições nacionais e apontou que Argentina, Espanha, China, Cuba, EUA, Finlândia, México, Portugal, Suécia e Suíça possuem gestão centralizada. Muito embora, a Espanha possua um sistema centralizado, se assenta no princípio da subsidiariedade que prevê gestão territorial-local. Cuba e Finlândia também se consideram centralizadas, mas possuem ampla participação da população local na gestão. Suécia prevê coordenação civil militar cooperada e Suíça possui coordenação local em nível de Cantões. As informações dos sites da Alemanha, Bangladesch, Brasil, França, Inglaterra, Itália, Rússia e Japão apontam que a Defesa Civil nestes países atua com gestão descentralizada e com Sistemas Nacionais de Proteção e Defesa Civil.

Quanto ao padrão de atuação. Segundo os sites das 18 instituições, a Defesa Civil saiu da abordagem de resposta e alívio para a Gestão de Risco de Desastres e no que tange ao padrão de organização (centralização, descentralização do processo decisório), segundo informações nos seus sites, a maioria não negligencia a dimensão civil, procurando garantir a participação social, atuando, inclusive, com voluntários.

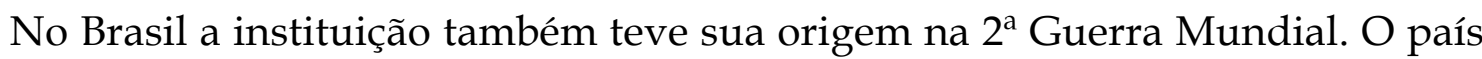
entrou no conflito após sofrer ataques, efetuados por um submarino alemão, em navios militares e em dois navios de passageiros. A população protestou, o Brasil entrou na guerra e começou a estruturar um sistema de defesa passiva para proteger a população 
em caso de outros ataques. No entanto, as primeiras Cartas Magmas do país apontam que, na época do Império já ocorriam ações de socorro à população em situações de emergência por seca ou inundações.

Ficou evidente a profunda heterogeneidade entre os Estados pesquisados, bem como fragilidades e desigualdades sociais inerentes a cada um. Na Região Nordeste, o Piauí vivencia sazonalmente secas muito graves desde os primeiros registros de sua colonização, a partir de 1674, por meio de concessão de sesmarias. Ao longo de sua história e processo de povoamento foram surgindo territórios de vulnerabilidades formando regiões que se pode chamar de clusters socioeconômicos (com populações muito pobres e/ou muito ricas). A vulnerabilidade aumenta a pobreza e os fluxos migratórios para cidades maiores do Estado. Há profunda relação entre a construção da vulnerabilidade e os padrões de ocupação e desenvolvimento do território, evidenciando que o problema da seca deve ser entendido para além do ponto de vista bio/físico/ambiental.

Na Região Norte, Rondônia foi colonizada por portugueses no século XVII e passou por diversos ciclos extrativistas que foram moldando o Estado povoado por meio de políticas do Governo Federal de incentivo à migração, posse e uso da terra. Os colonos eram obrigados a desmatar e queimar para obter a posse das terras. O processo de ocupação do espaço e utilização dos recursos da natureza, o desmate e o fogo produziram o território de desastres. As políticas de incentivo adotadas pelo Governo federal transformaram o Estado em campo para os latifundiários e para o agronegócio, que hoje impulsiona a economia do Estado, o desmatamento e as queimadas, dando continuidade ao processo de vulnerabilização do território e das populações que vivem não só no Estado, mas em toda região Amazônica.

Santa Catarina teve sua formação com a instituição das capitanias hereditárias numa das Regiões do país que, juntamente com a Região Sudeste, mais sofre com os fenômenos das enxurradas e inundações, a Região Sul. O Estado possui relevo acidentado e coordenadas de fenômenos extremos frequentes e intensos. É um dos Estados do Brasil mais atingidos por vendavais, tornados, granizos e deslizamentos. $\mathrm{O}$ aumento do número de enchentes, principalmente no Sul do Estado e na Região do Vale do Itajaí-Açu, acompanhou a dinâmica de exploração do espaço geográfico no Estado. Ou seja, o processo de ocupação do território e a forma de utilização dos recursos construiu a vulnerabilidade territorial e produziu o território do desastre.

No Piauí os primeiros registros de uma Defesa Civil institucionalizada são de 2003, com a promulgação da Lei Complementar no 28/2003 e esta foi a Lei analisada na pesquisa. Em Rondônia, a história da Defesa Civil se confunde com a fundação do Corpo de Bombeiros estadual e do próprio Estado. A previsão legal data da Constituição 
do Estado de Rondônia em 1989. Para fins de análise, foi considerado o Decreto no 9.136/2000, atualmente em vigor. Em Santa Catarina a Defesa Civil foi fundada em 1973 por meio da Lei no ${ }^{4} .841$, que também instituiu a Coordenadoria Estadual da Defesa Civil (Cedec) e para fins de análise, foi estudada a Lei Complementar no 741/2019.

Em nível federal, no dia 10 de abril de 2012, foi aprovada a Lei no 12.608 que instituiu a atual Política Nacional de Proteção e Defesa Civil, dispôs sobre o Sistema Nacional de Proteção e Defesa Civil (SINPDEC), o Conselho Nacional de Proteção e Defesa Civil (CONPDEC) e autorizou a criação de um sistema de informações e monitoramento de desastres no país. A PNPDEC foi a Lei federal analisada na pesquisa, juntamente com as Leis Estaduais.

Conforme os resultados, as instituições de Defesa Civil do Piauí, Rondônia e Santa Catarina possuem histórias e formas de organização distintas. No entanto, também possuem alguns pontos em comum, como o fato de terem sido instituídas sob a égide da Polícia Militar e do Corpo de Bombeiros Militar de seus Estados. Nos três Estados as instituições desvincularam-se da Polícia Militar. O mesmo ocorreu com o Corpo de Bombeiros Militar no Piauí e Santa Catarina, mas em Rondônia a Defesa Civil ainda está vinculada ao comando-maior desta instituição.

Como explicitado na metodologia desta pesquisa, foi realizado uma análise tridimensional da gestão da vulnerabilidade aos desastres no Brasil. Considerou-se três dimensões, a saber: a dimensão Política, Setorial e Espacial. A análise deu-se por meio de um Comparativo Externo e Interno da Defesa Civil nos três Estados. O ponto de partida da análise foi a PNPDEC, juntamente com as leis estaduais de Defesa Civil já citadas. Na dimensão Setorial considerou-se a percepção dos entrevistados sobre a Política.

Os resultados evidenciam que o processo de formação e desenvolvimento da Defesa Civil tem um movimento duplo. De um lado, a institucionalização. De outro lado, a centralização. A centralização inviabiliza ou torna incipiente a participação social (sociedade organizada e comunidade científica) e a gestão territorial-local, premissas da Gestão de Risco de Desastres elencadas nos Marcos de Hyogo e Sendai. Isso já foi constatado, por meio dos estudos comparativos de Luckie (1970), como visto. A Política Nacional de Proteção e Defesa Civil instituída pela Lei no 12.608, de 2012, define que o órgão central de coordenação das ações de proteção e Defesa Civil no território nacional é a Secretaria Nacional de Proteção e Defesa Civil (SEDEC) (BRASIL, 2017). No entanto, os resultados apontaram que a coordenação pode estar sendo confundida com centralização, como evidenciaram alguns dos entrevistados na pesquisa de campo.

Outro processo apontado nos resultados e que contribui para a centralização é a militarização da instituição. No mundo todo, a estrutura da Defesa Civil sempre esteve 
ligada às instituições militares, conformando a instituição (MOREIRA, 2011). como constatou-se nos sites da Defesa Civil de 18 países. No Brasil, nos três estados estudados, a Defesa Civil foi gestada na égide das Polícias Militares estaduais, marcadas pela dominação masculina, burocrática, de estrutura hierárquica e segmentadora, fundadas na ordem e obediência (MOREIRA, 2011). Embora houve a desvinculação, militares ainda são mantidos no comando das instituições. Os que defendem a militarização na gestão dos desastres argumentam que o Estado necessita desse poder de polícia. Entendem que esse poder é o instrumento essencial para impor limites entre o direito individual e o coletivo e frear abusos (MEIRELES, 2009). No entanto, a Defesa Civil não necessita de centralização, mas de coordenação.

Quanto à tecnificação ${ }^{4}$, o estudo apontou que esta pode ser positiva e negativa. Positiva, ao possibilitar o aprimoramento de procedimentos, qualificar análises, monitoramento, informação e ação. Negativa, quando a técnica não reduz a vulnerabilidade ao risco e ao impacto do desastre ou, ainda, o intensifica. Se há "assimetria de acesso às informações, às tecnologias adaptativas", o não-acesso ou a não-compreensão da informação, a população "é induzida a pensar que se encontra protegida pela competência [...] e pela qualidade das especificações técnicas" e pode acontecer de "a ciência e as tecnologias modernas" estarem "diretamente envolvidas na produção do risco, contribuindo para a produção e a legitimação de riscos modernos" (VALÊNCIO et al., 2009, p. 149). Então, o que poderia contribuir para a redução do risco e da perda de vidas por desastres, atua de forma a intensificá-lo, acentuando o lado negativo da tecnificação. Isso não diminui a necessidade do uso das tecnologias na gestão e da formação em nível de equipes e capacitação da comunidade.

No que tange a articulação, a dimensão Setorial apontou que ela não ocorre como deveria porque ainda não diálogo suficiente entre as instituições dos diferentes entes federados. O mesmo ocorre com a integração que foi tida como possível, mas de que ela ocorra na lógica da sociedade civil permitindo a ruptura de paradigmas. Viu-se que a Política nacional prevê a participação social na gestão na busca de uma atuação sistêmica e integrada, no entanto, a realidade apontada pelos entrevistados denota a incipiência da participação da sociedade civil na gestão, tanto no que tange à comunidade científica, como da sociedade em geral.

$\mathrm{Na}$ análise da dimensão Espacial, considerando-se a dimensão Política, verificou-se que a Lei no 12.608 estabelece a necessidade da gestão territorial, no entanto, não a especifica. Ou seja, não aponta a que tipo de território se refere, se geográfico, político

4 Formação de equipes técnicas e aparelhamento tecnológico da instituição. 
ou administrativo. Além disso não conceitua território e nem como compreende essa gestão territorial.

Também foram citados avanços como a busca da gestão compartilhada e intergovernamental, da articulação entre os entes federados, da integração com outras políticas públicas (ordenamento territorial, desenvolvimento regional etc.) e a previsão de ênfase na prevenção. No entanto, segundo o setor técnico, especializado e comunitário. o êxito do parâmetro propositivo da Política depende do aprofundamento da articulação, da cooperação e da integração dos entes e com a sociedade civil, inserindo-a na Gestão.

\section{Considerações finais}

Na introdução deste artigo foram apresentadas informações, em escala global e nacional da base de dados das pesquisas do Em-Dat (Emergency Events Database) sobre o aumento da frequência e da intensidade dos desastres no mundo e no Brasil. Entende-se desastres como uma construção social e ratifica-se a crítica à necessidade de sua desnaturalização. Os dados do Em-Dat, servem de referência para nortear políticas de prevenção e ações governamentais de gerenciamento de risco e de desastres em todos os níveis de gestão.

No Brasil, as pesquisas sobre os desastres cresceram em várias áreas do conhecimento, como a antropologia, a ciência política e a sociologia. A inserção dos estudos nas Ciências Sociais ainda é tímida, no entanto, já houve avanços. Pesquisas em desastres são urgentes e necessárias pois permitem compreender a dinâmica de incidência e impacto dos eventos e, além de nortear, possibilitam refinar políticas públicas e ações governamentais de enfrentamento na área. Já foi dito da importância de que os estudos foquem nos fatores de risco e na vulnerabilidade dos territórios e populações.

A desconsideração da vulnerabilidade pode contribuir para a diminuição da resiliência da população, o aumento do risco, a frequência e a intensificação do impacto dos desastres, além de aumentar os danos e prejuízos decorrentes destes. No que tange à gestão dos desastres no Brasil, a Defesa Civil é a instituição detentora da primazia nas ações governamentais de monitoramento e gerenciamento de risco que se dá em cinco fases: prevenção, mitigação, preparação, resposta e recuperação. Suas ações, preconizadas na Política Nacional de Proteção e Defesa Civil (BRASIL, 2012) permeiam a busca pelo fortalecimento das instituições que atuam nos três níveis de gestão no País. É onde entra a comunidade acadêmica científica que, por meio da pesquisa e extensão, poderia contribuir muito com a produção do conhecimento sobre desastres. A incorporação do 
conhecimento científico na gestão dos desastres possibilitaria mudanças referenciadas nos Marcos de Ação de Hyogo e Sendai.

No entanto, o estudo comparativo, cujas estratégias analíticas/metodológicas foram neste artigo explicitadas, apontaram que a militarização está incorporada nos altos cargos da Defesa Civil nos três casos estudados, resultando na centralização do processo decisório sobre desastres neste nível de gestão, comprometendo a participação social. Apontaram ainda que a tecnificação, que tanto pode promover o aprimoramento do monitoramento do risco e qualificar as ações em caso de desastres, também pode causar uma falsa sensação de segurança para a população, aumentando sua exposição ao risco o ao impacto dos desastres. Os resultados apresentados estão conectados entre si e com o tema abordado neste artigo e apontam para a necessidade da descentralização do processo decisório e a capilarização das ações em desastres, bem como, para o desafio de ampliar e consolidar o debate referente às pesquisas sobre desastres na área das Ciências Socais e a utilização de estudos comparativos nestes campos.

\section{Referências bibliográficas}

ALBALA-BERTRAND, José M. The political economy of large natural disasters. Oxford: Clarendon Press, 1993.

AMIN, Samia; GOLDSTEIN, Markus. (Org). Data against disasters: establishing effective systems for relief, recovery, and reconstruction. Washington DC. The World Bank, 2008.

ANDERSON, Mary. "Vulnerability to disaster and sustainable development: a general framework for assessing vulnerability". In: MUNASINGHE, M.; CLARKE, C. (Eds.). Disaster Prevention for Sustainable Development: Economic and Policy Issues. Washington, DC: The World Bank, 1995. pp 42-59.

AZEVEDO, Franco C. E.; OLIVEIRA, Leonel G. L.; GONZALES, Rafael K.; ABDALLA, Márcio M. A estratégia de triangulação: objetivos, possibilidades, limitações e proximidades com o pragmatismo. Anais do IV Encontro do Ensino e Pesquisa em Administração e Contabilidade. Brasília, DF - 3 a 5 de novembro de 2013.

BABBIE, Earl. Survey research methods. 2.ed. California: Wadsworth Publishing Company, 1990.

BABBIE, Earl; MOUTON, Johann. The practice of social research. Cape Town: Oxford. University Press. Baeck, L. 2001.

BADIE, Bertrand; HERMET, Guy. Politica Comparada. México: Fondo de Cultura Económica, 1993.

BENDIX, Reinhard. National Bullding and Citizenship. Los Angeles: University of California Press. 1977.

BARDIN, Laurence. L'Analyse de contenu. Editora: Presses Universitaires de France, 1977.

BEREDAY, George. Z. F. El método comparativo en pedagogía. Barcelona: Herder, 1968.

BEUREN, Ilse M. (Org.). Como Elaborar Trabalhos Monográficos em Contabilidade, 2ª ed., São Paulo: Atlas S.A., 2004.

BOHN, Norma; MATTEDI, Marcos A.; AUMOND, José; SEVERO, Dilceu L.; DOURADO, F.; 
CHAPLOT, Vincent.; GRIMALDI, Michele. Climate changes: past, present and future: trends variability and impacts bilateral ird-cnpq and tripartite France-Brazil-Africa Meeting Cooperative Projects. October 10-12, 2012 Agadir Morocco. 2012.

BULGACOV, Sérgio. Estudos comparativo e de caso de organizações de estratégias. O\&S, 5(11), 1998, p. 56-73. Disponível em: https:// periodicos.ufba.br/index.php/revistaoes/ article/view/10375/7394.

BRASIL. Lei no 12.608, de 20 de abril de 2012. Institui a Política Nacional de Proteção e Defesa Civil - PNPDEC, dispõe sobre o Sistema Nacional de Proteção e Defesa Civil - SINPDEC e o Conselho Nacional de Proteção e Defesa Civil - CONPDEC, autoriza a criação de sistema de informações e monitoramento de desastres e dá outras providências. Presidência da República, Casa Civil, Subchefia para Assuntos Jurídicos. Brasília/DF, 2012.

BRASIL. Ministério da Integração Nacional. SEDEC. Departamento de Minimização de Desastres. Módulo de formaçao: reconstrução: gestão de recursos federais em proteção e defesa civil para reconstrução: livro base / Ministério da Integração Nacional, SEDEC, Departamento de Minimização de Desastres. Brasília: MI, 2017.

CARMO, Roberto; VALENCIO, Norma. Segurança humana no contexto de desastres. São Carlos: RiMa Editora, 2014.

CEMADEN. Centro Nacional de Monitoramento e Alertas de Desastres Naturais. Principais tipos de ameaças no Brasil. CEMADEN. Monitoramento, São José dos Campos, SP. 2014.

CEPED. Centro Universitário de Estudos e Pesquisas sobre Desastres. Relatório de danos materiais e prejuizos decorrentes de desastres naturais no Brasil: 1995 - 2014. Centro Universitário de Estudos e Pesquisas sobre Desastres. Universidade Federal de Santa Catarina. Banco Mundial (Organização Rafael Schadeck) - Florianópolis: CEPED UFSC, 2016.

CLIFFORD, Roy. “The bio grande flood: a comparative Study of border camunities". In: Disaster. Washington, D.C.: National Academy of Sciences. 1956. pp.

CRESWELL, John W. Projeto de Pesquisa: métodos qualitativos, quantitativo e misto. Porto Alegre: Artmed, 2010.

DYNES, Russel R. The comparative study of disaster: a social organizational approach. University of Delaware. EUA, 1971.

EM-DAT. The International Disaster Database. Centre for Research on the Epidemiology of Disaster (CRED). Bruxelas, Bélgica. 2020.

FAAS, Albert J.; BARRIOS, Roberto. Applied anthropology of risk, hazards, and disasters. Human Organization, 74(4), 2015, p. 287-295. Disponível em: https:/ / www.jstor.org/stable/26536807.

FRANCO, Maria C. Quando nós somos o outro: questões teórico-metodológicas sobre os estudos comparados. Educação e Sociedade, XXI(72), 2000, p. 197-230. Disponivel em: https:/ / www.scielo.br/j/es/a/xGMSnNdj7LYCdPrgFNp7C5Q/?format=pdf\&lang=pt.

GALL, Melanie; NGUYEN, Khai. H; CUTTER, Susan. L. Integrated research on disaster risk: is it really integrated? International Journal of Disaster Risk Prevention, 12, 2015, p. 255-267. Disponível em: https://www.sciencedirect.com/science/article/abs/pii/S2212420915000138.

GONZALEZ, Rodrigo S. O método comparativo e a Ciência Política. Revista de Estudos e Pesquisas sobre as Américas, 2(1), 2008, p. 1-12. Disponível em: https:// periodicos.unb.br/index. php/repam/article/view/16160.

IPCC. Painel Intergovernamental Sobre Mudanças Climáticas. WGH AR5 - Climate Change 2014: impacts, adaptation, and Vulnerability - Summary for Policymakers. 2014.

LAVELL, Allan. Los conceptos, estudios y práctica en torno al tema de los riesgos y desastres en América Latina: evolución y cambio, 1980-2004: el rol de la Red, sus miembros y sus instituciones de apoyo. In: La gobernabilidad en América Latina: balance reciente y tendencias a futuro. Curridabat: Facultad Latinoamericana de Ciencias Sociales, 2005. pp. 1-66. 
LUCKIE, Benjamin. A study of functional response to stress in three societies. Unpublished Ph.D. dissertation. Columbus: The Ohio State Universcty. 1970.

MARANDOLA, Eduardo Jr.; HOGAN, Daniel. J. Natural hazards: o estudo geográfico dos riscos e perigos. Ambiente $\mathcal{E}$ Sociedade, 7(2), 2004, p. 95-110. Disponível em: https://www. scielo.br/j/asoc/a/jY8HBwMg4rJJP49Z6zH9RdJ/abstract/?lang=pt.

MARCELINO, Emerson. V.; RUDORFF, Frederico. de M.; MARCELINO, Isabela. P. V. de O.; GOERL, Roberto. F.; KÖBIYAMA, Masato. Impacto do furacão Catarina sobre a região Sul catarinense: monitoramento e avaliação pós-desastre. Geografia, 30(3), 2005, p. 559-582. Disponível em: https:/ / www.periodicos.rc.biblioteca.unesp.br/index.php/ageteo/article/ view/651/548.

MARCHEZINI, Vitor. As Ciências Sociais nos desastres: um campo de pesquisa em construção. BIB, 83(1), p. 43-72, 2017.

MARCHEZINI, Vitor. Publicação discute a importância das Ciências Sociais nos estudos para a redução dos desastres socioambientais. In: CEMADEN. Centro Nacional de Monitoramento e Alertas de Desastres Naturais. Publicada em 18 de maio de 2018. Disponível em: http:/ / www.cemaden.gov.br/publicacao-discute-a-importancia-das-ciencias-sociais-nos-estudos-para-a-reducao-dos-desastres-socioambientais/ Acesso em: 17 jan. 2021.

MATTEDI, Marcos. A. As enchentes como tragédias anunciadas: impacto da problemática ambiental nassituações de emergênciaem Santa Catarina. Tese de Doutorado. Programa de Pós-Graduação em Ciências Sociais, Instituto de Filosofia e Ciências Humanas da Universidade Estadual de Campinas, 1999.

MATTEDI, Marcos. A.; BUTZKE, Ivani. C. A relação entre o social e o natural nas abordagens de hazards e de desastres. Ambiente E Sociedade, 9, 2001, p. 10-21. Disponível em: https:/ / repositorio.unesp.br/handle/11449/30418.

MARSHALL, Gordon. Dictionary of sociology. Oxford: Oxford University Press, 1998.

MAXQDA. The Art of Data Analisys. Sobre o MAXQDA. Site Oficial. Disponível em: https:// www.maxqda.com/brasil/software-analise-qualitativa?gclid=EAIaIQobChMIo-uK78_s6wIVCAeRCh2yWg7rEAAYASAAEgLTv_D_BwE Acesso em: 15 dez. 2020.

MEIRELES, Hely L. Direito administrativo brasileiro. São Paulo: Malheiros, 2009.

MI. Ministério da Integração Nacional. Secretaria Nacional de Defesa Civil (SEDEC). Manual de desastres humanos: desastres humanos de natureza tecnológica - v. 2. - I parte / Ministério da Integração Nacional. Secretaria Nacional de Defesa Civil. - Brasília: MI, 2003.

MINAYO, Maria C. de S. O desafio do conhecimento: pesquisa qualitativa em saúde. 14ª ed. São Paulo: Hucitec, 2014.

MOREIRA, Nádia X. Instituições militares: uma análise sociológica. Rio de Janeiro, 2011. Não publicado.

ONU. Organização das Nações Unidas. Marco de Sendai para a Redução do Risco de Desastres 2015-2030. Anais da III Conferência Mundial sobre a Redução do Risco de Desastres, realizada de 14-18 de março de 2015, em Sendai, Miyagi, no Japão. 2015.

OPAS-OMS. Organização Pan-Americana da Saúde-Organização Mundial da Saúde. Folha Informativa COVID-19 - Escritório da OPAS e OMS no Brasil. OPAS-OMS, publicada em 14 de dezembro de 2020. Disponível em: https://www.paho.org/pt/covid19\#: :text=Em\%20

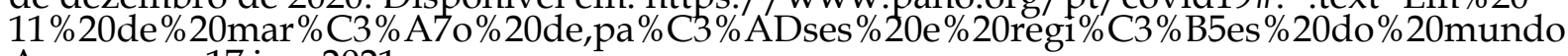
Acesso em: 17 jan. 2021.

PERRY, Ronald W.; QUARANTELLI, Enrico L. What is a disasters? New answers to old questions. Bloomington, In: USA: Xlibris, Corporaton, 2005. pp. 325-396.

PRINCE, Samuel H. Catastrophe and social change: based upon a sociological study of the Halifax disaster. Doctoral Dissertation. Department of Political Science, Columbia University, 1920. 
PRONKO, Marcela. A comparação como ferramenta de conhecimento e os processos de integração supranacional: desafio para as Ciências Sociais. s/d, pp. 573-594. Disponível em: http://www. epsjv.fiocruz.br/upload/docs/Artigo\%201.pdf. Acesso em: 22 jan. 2021.

QUARANTELLI, Enrico L. Disasters: theory na research. Beverly Hülls: Sage, 1978.

QUARANTELLI, Enrico L. Community crises: an exploratory comparison of the characteristics and consequences of disasters and riots. Journal of Contingencies and Crisis Management, 1, 1993, p. 67-78. Disponível em: https:// onlinelibrary.wiley.com/ doi/10.1111/j.1468-5973.1993.tb00009.x.

QUARANTELLI, Enrico L.; DYNES, Ronald. Response to Social Crisis and Disaster. Annual Review of Sociology, 3, 1977, p. 23-49. Disponivel em: https:/ / www.annualreviews.org/ doi/10.1146/annurev.so.03.080177.000323.

QUARANTELLI, Enrico L. L. Disasters: theory na research. Beverly Hülls: Sage, 1978.

QUARANTELLI, Enrico L. Uma agenda de pesquisa do século 21 em Ciências Sociais para os desastres: questões teóricas, metodológicas e empíricas, e suas implementações no campo profissional. Tradução: Raquel Brigatte. O Social em questão, XVIII(33), 2015, p. 25-56.

RICHARDSON, Roberto J. Pesquisa social: métodos e técnicas. São Paulo: Atlas, 1989.

ROMERO, Juan J. F.; FERNÁNDEZ, Vanesa R. Una revisión bibliográfica de los estudios comparativos. Su evolución y aplicación a la ciencia de las bibliotecas. Revista Interamericana Biblioteca Medellín, 32(2), 2009, p. 411-433. Disponível em: http:/ /www.scielo.org.co/pdf/ $\mathrm{rib} / \mathrm{v} 32 \mathrm{n} 2 / \mathrm{v} 32 \mathrm{n} 2 \mathrm{a} 15 . \mathrm{pdf}$.

SANTOS, André M. dos. Quando comparamos para explicar Desenhos de pesquisa e sequências temporais na investigação de instituições políticas. $R B C S$, 27(80), 2012, p. 203-260. Disponível em: https: / / www.scielo.br/j/rbcsoc/a/ cTrd8grDV65XkzVY4j7swyN/?format=pdf\&lang=pt.

SARTORI, Giovanni. Método Comparativo e Política Comparada. In: A política: lógica e método nas Ciências Sociais. Brasília: Ed UNB, 1997. pp. 203-246.

SARTORI, Giovanni; MORNILO, Leonardo. "Comparación y método comparativo". In: SARTORI, Giovanni; MORNILO, Leonardo. (Comps.). La Comparación en las ciencias sociais. Madri: Alianza Editorial, 2002. pp.

SAUNDERS, Mark; LEWIS, Philip; THORNHILL, Adrian. Research methods for business students. Harlow: Pearson Education Limited. 2012.

SEDEC. Secretaria Nacional de Proteção e Defesa Civil. A Defesa Civil no Brasil e no mundo. Publicado no dia 20 de setembro de 2012, às 17:28 hs, revisado em 11 de abril de 2016, às 08:19 hs, online. Proteção e Defesa Civil. Secretaria Nacional de Proteção e Defesa Civil. Ministério de Integração Nacional, Brasília/DF, 2016. Disponível em: http:/ /www.integracao.gov.br/defesa-civil-no-brasil-e-no-mundo. Acesso em: 02 jul. 2021.

SCHNEIDER, Sérgio; SCHMITT, Claudia J. O uso do método comparativo nas Ciências Sociais. Cadernos de Sociologia, 9, 1998, p. 49-87. Disponível em: https:/ / elizabethruano.com/ wp-content/uploads/2018/08/schneider-schimitt-1998-o-uso-do-metodo-comparativo-nas-ciencias-sociais.pdf.

SILVA, Fabyani de C. T. Estudos comparados como método de pesquisa: a escrita de uma história curricular por documentos curriculares. Revista Brasileira de Educação, 21(64), 2016, p. 209-224. Disponível em: https:/ / www.scielo.br/j/ rbedu/a/5YDbJGbDWRkkTr8bDhvZnBh/abstract/?lang=pt.

SILVA, Cristhian T.; BARROS, Flávia L. de. Estudos comparados sobre as Américas - Resenhas. In: BARROS, Flávia L. de; SILVA, Cristhian T. Estudos Comparados nas Ciências Sociais - Resenhas. Série Ceppac, n. 32, Brasília: CEPPAC/UnB, 2011.

SOUZA, Felipe. O que é o 'ciclone bomba' que está causando estragos no Sul do Brasil. Publicado no dia 30 de junho de 2020, às 20h50. BBC News, Santa Catarina, 2020. Disponível em: 
https://g1.globo.com/sc/santa-catarina/noticia/2020/06/30/o-que-e-o-ciclone-bomba-que-esta-causando-estragos-no-sul-do-brasil.ghtml. Acesso em: 03 set. 2020.

UFSC. Universidade Federal de Santa Catarina. Centro Universitário de Estudos e Pesquisas sobre Desastres. Atlas brasileiro de desastres naturais: 1991 a 2012 / Centro Universitário de Estudos e Pesquisas sobre Desastres. 2. ed. revisão ampliada - Florianópolis: CEPED/UFSC, 2013.

VALENCIO, Norma; SIENA, Mariana; MARCHEZINI, Victor; COSTA, Juliano G. Sociologia dos desastres - construção, interfaces e perspectivas no Brasil. São Carlos: RiMa Editora, 2009.

WENGER, Dennis E. “Community response to disaster”. In: QUARANTELI, Enrico L. (ed.) Disasters: Theory and Research, Bervely Hills CA: Sage. 1978. pp.

WHITE, Gilbert F. “Natural hazards research”. In: CHORLEY, R. J. (ed.) Directions in Geography [Chorley, R. J. (ed)]. London, UK: Methuen and Co, 1973. pp. 193-216.

WOORTMAN, Ellen. Comparação, método comparativo e família. In: $22^{\circ}$ Encontro Anual da ANPOCS, s/d. Disponível em: http://anpocs.org/index.php/encontros/papers/ 22-encontro-anual-da-anpocs/gt-20/gt05-18/5071-ellenwoortmann-comparacao/ file Acesso em: 22 jan. 2021.

YIN, Robert K. Estudo de caso: planejamento e métodos. Porto Alegre: Bookman, 2001. 